\title{
A requiem for the cholecystokinin provocation test?
}

A Smythe, A W Majeed, M Fitzhenry, A G Johnson

\begin{abstract}
Background-The cholecystokinin provocation test (CCKPT) has been claimed to predict a better symptomatic result after cholecystectomy in patients with acalculous biliary pain.

Aims-To examine the predictive value of the CCKPT for symptom relief after cholecystectomy in both CCKPT positive and negative patients.

Patients and methods-Fifty eight patients with acalculous biliary pain underwent CCKPT with serial ultrasound gall bladder volumetry. CCKPT positive patients were offered cholecystectomy; negative patients were reassessed and were offered a cholecystectomy if symptoms persisted. Six months after cholecystectomy, the CCKPT was repeated.

Results-Of 32 CCKPT positive patients, 27 underwent cholecystectomy and of these, $18(67 \%)$ became symptom-free. Postoperatively, 20 of 25 patients converted to CCKPT negative but five remained CCKPT positive and were symptomatic. Of the 26 CCKPT negative patients, nine became symptom-free without cholecystectomy; six of 14 (42.8\%) patients undergoing cholecystectomy became asymptomatic and remained CCKPT negative. Cholecystectomy seemed to reduce symptoms in both groups, but there was no significant difference in the symptomatic outcome between preoperative CCKPT positive and negative patients.
\end{abstract}

Conclusions-In this study, cholecystokinin provocation testing did not predict symptomatic benefit from cholecystectomy and we suggest it should no longer be used in the evaluation of patients with acalculous biliary pain.

(Gut 1998;43:571-574)

Keywords: cholecystectomy; cholecystokinin; symptoms

Acalculous biliary pain (ABP) is a clinical syndrome in which patients present with symptoms of "typical" gallstone pain (pain in the right hypochondrium, often related to meals) but gallstones are not visible on ultrasonography and endoscopy is normal. It is presumed that this pain is caused by dysmotility of the gall bladder, the neck contracting asynchronously with the body resulting in a functional obstruction. Unfortunately, the symptomatic outcome from cholecystectomy in these patients has varied widely in numerous studies. ${ }^{1-6}$
In an attempt to improve postoperative outcome, the cholecystokinin provocation test (CCKPT) was introduced. ${ }^{1}$ The rationale behind this test is that patients whose pain is reproduced by stimulating the gall bladder have gall bladder dyskinesia and would benefit from cholecystectomy. The selection of patients on the basis of the CCKPT does not seem to have improved the results from cholecystectomy ${ }^{78}$ despite some claims of its efficacy, ${ }^{9}{ }^{10}$ although these did not include outcomes after cholecystectomy in patients whose CCKPTs were negative. ${ }^{11}$ We have examined the predictive value of this test for symptom relief after cholecystectomy, and have performed cholecystectomy on both CCKPT positive and negative patients. The CCKPT was repeated on all patients six months after operation to establish the proportion of patients who did not benefit from cholecystectomy despite a positive CCKPT.

Patients and methods

All patients included in the study had suffered numerous episodes of upper right quadrant pain and a clinical diagnosis of acalculous biliary pain had been made on the basis of normal abdominal ultrasonography and normal upper gastrointestinal endoscopy. They were then referred for a CCKPT. Any patient found to have gallstones either on preoperative imaging or at surgery was excluded from analysis.

ASSESSMENT OF SYMPTOMS

Before commencement of the CCKPT, a detailed symptom analysis was carried out using the McGill Pain Questionnaire (MPQ), ${ }^{12}$ designed to provide a quantitative measure of clinical pain which can be analysed statistically. From this questionnaire the total number of words (total word score, TWS: scale 0-20) used to describe any pain, a weighted pain rating index (PRI, scale 0-3 for each word), and a visual analogue score (VAS, scale 0-100) for pain were noted.

The CCKPT was carried out on these patients after an overnight fast; they received an intravenous infusion of saline followed by an infusion of $0.05 \mu \mathrm{g} / \mathrm{kg}$ body weight CCK-10 (Takus, Pharmacia Ltd, Milton Keynes, UK) in $10 \mathrm{ml}$ of saline over 10 minutes. Patients were not aware of which solution was being given, and during the infusion a careful record of their symptoms was made. The CCKPT was considered positive only when the patient's usual right upper quadrant pain was reproduced after infusion of CCK. Any other abdominal discomfort was recorded but did not contribute to a positive test. 
Table 1 McGill Pain Questionnaire scores before and after CCK provocation testing

\begin{tabular}{|c|c|c|c|c|c|c|}
\hline & \multicolumn{3}{|c|}{ Before CCK injection } & \multicolumn{3}{|c|}{ After CCK injection } \\
\hline & VAS & $T W S$ & PRI & VAS & $T W S$ & PRI \\
\hline $\mathrm{CCKPT}_{1}$ positive & $5.2(16.4)$ & $0.5(1.6)$ & $0.9(3.0)$ & $57.8(23.4)^{\star}$ & $6.0(5.2)^{\star}$ & $12.4(13.0)^{\star}$ \\
\hline $\mathrm{CCKPT}_{1}$ negative & $7.0(21.7)$ & $0.6(2.0)$ & $1.2(4.4)$ & $9.2(21.6)$ & $0.9(2.1)$ & $1.8(4.4)$ \\
\hline $\mathrm{CCKPT}_{2}$ positive & $5.2(14.5)$ & $1.0(2.7)$ & $3.1(9.6)$ & $15.8(26.2)$ & $1.4(2.6)$ & $3.9(9.1)$ \\
\hline
\end{tabular}

Results are expressed as mean (SD). Comparisons before and after CCK injection are made using a paired $t$ test. ${ }^{\star} \mathrm{p}<0.001$.

VAS, visual analogue score; TWS, total word score; PRI, pain rating index.

ASSESSMENT OF GALL BLADDER EMPTYING

Ultrasonography of the gall bladder was carried out and gall bladder wall thickness and volume were calculated. The scans were repeated before and after saline infusion, at the onset of pain (if reproduced), and at 15, 45, and 60 minutes after CCK infusion.

Patients in whom saline reproduced the pain were treated as those whose CCKPT was negative. Patients whose pain was reproduced after CCK infusion (CCKPT positive) were offered a cholecystectomy. CCKPT negative patients were interviewed six months after the test and were also offered a cholecystectomy at that time if their upper right quadrant symptoms had persisted. In all patients, the CCKPT was repeated six months after cholecystectomy using the same dose of CCK-10 with preinfusion and postinfusion symptom questionnaires. The postoperative test was considered positive if the patient's original right upper quadrant pain was reproduced and negative if no pain was present. In addition, patients were specifically asked whether the removal of the gall bladder had resulted in symptom relief.

\section{Results}

Over a four year period, 58 patients (47 women and 11 men) with a median age of $46(18-57)$ years were entered into the study. All had right upper quadrant pain (duration 2-132 months, median 15.0 months). One patient who had small $(0.5 \mathrm{~mm})$ gallstones discovered at the time of surgery (with negative preoperative imaging) was excluded from analysis.
PREOPERATIVE CCKPT $\left(\right.$ CCKPT $\left._{1}\right)$

Of the 58 patients entered into the study, 32 were positive $\left(\mathrm{CCKPT}_{1}\right.$ positive) and 26 were negative (CCKPT ${ }_{1}$ negative) for reproduction of pain with CCK infusion. Three patients whose test was positive for saline infusion were included in the $\mathrm{CCKPT}_{1}$ negative group. Table 1 shows the MPQ scores for reproduction of pain (but not for overall symptoms). All scores were significantly higher immediately after CCK infusion in $\mathrm{CCKPT}_{1}$ positive patients when compared with preinfusion scores, but there was no significant difference between preinfusion and postinfusion scores in the $\mathrm{CCKPT}_{1}$ negative group. There was also a significant difference in the post-CCK infusion MPQ scores between $\mathrm{CCKPT}_{1}$ positive and the CCKPT ${ }_{1}$ negative patients $(\mathrm{p}<0.0001$ for TWS, PRI, and VAS, paired $t$ test).

Of the $32 \mathrm{CCKPT}_{1}$ positive patients, 27 underwent cholecystectomy. The $26 \mathrm{CCKPT}_{1}$ negative patients were reviewed at six months, and 14 with persistent symptoms subsequently underwent cholecystectomy.

POSTOPERATIVE CCKPT (CCKPT $\left.{ }_{2}\right)$

Twenty five of $27 \mathrm{CCKPT}_{1}$ positive patients who underwent cholecystectomy returned for a postoperative CCKPT $\left(\mathrm{CCKPT}_{2}\right)$ six months later. Of these, 20 had a negative test for pain after saline or CCK infusion. Five patients had a positive $\mathrm{CCKPT}_{2}$ despite gall bladder removal (fig 1) and all still complained of their original symptoms.



Figure 1 Clinical outcome of patients undergoing CCKPT. 
Table 2 McGill Pain Questionnaire scores before and after cholecystectomy

\begin{tabular}{lccc}
\hline Score & Preoperative & $\begin{array}{l}\text { 6 months } \\
\text { postoperative }\end{array}$ & p Value \\
\hline CCKPT positive patients & & \\
VAS & $70.9(22.4)$ & $20.7(28.7)$ & $<0.0001$ \\
TWS & $11.4(17.5)$ & $1.8(2.7)$ & 0.02 \\
PRI & $17.6(7.5)$ & $4.6(9.0)$ & $<0.0001$ \\
CCKPT negative patients & & \\
VAS & $67.6(28.6)$ & $14.5(24.9)$ & 0.008 \\
TWS & $7.2(3.7)$ & $1.7(2.9)$ & 0.006 \\
PRI & $23.8(22.6)$ & $2.5(4.6)$ & 0.013 \\
\hline
\end{tabular}

Results expressed as mean (SD). Comparisons made using the paired $t$ test.

Of the $14 \mathrm{CCKPT}_{1}$ negative patients who underwent cholecystectomy, 11 underwent a repeat CCKPT six months after surgery and all remained CCKPT negative (fig 1). There was no significant difference between the pretest and post-test MPQ scores in this group.

GALL BLADDER EMPTYING AND WALL THICKNESS The mean (SD) percentage gall bladder emptying was $32.9(4.2) \%$ in patients who experienced pain after the first infusion of CCK and 52.0 (6.2)\% for patients who did not ( $\mathrm{p}=0.01, t$ test). There was no correlation between gall bladder emptying and symptom benefit after cholecystectomy.

Mean (SD) gall bladder wall thickness was $1.6 \mathrm{~mm}(0.7 \mathrm{~mm})$ for CCKPT positive patients and $1.7 \mathrm{~mm}(1.0 \mathrm{~mm})$ for CCKPT negative patients ( $p=0.7, t$ test). There was no significant association between gall bladder wall thickness and postoperative symptom benefit.

\section{SYMPTOMATIC OUTCOME}

There was no significant difference between the symptomatic outcome after cholecystectomy between preoperatively CCKPT positive or negative patients ( $\mathrm{p}=0.48, \chi^{2}$ test). Overall, cholecystectomy in these patients seemed to be associated with a significant reduction in symptoms in both groups, as shown in table 2 . The sensitivity of the CCKPT in the prediction of symptom relief after cholecystectomy was $56.2 \%$ and the specificity was $57.1 \%$ although the numbers are relatively small.

There was no correlation between the total duration of symptoms and symptom relief after cholecystectomy $\left(r_{\mathrm{s}}=-0.18, \mathrm{p}=0.9\right.$, Spearman's correlation coefficient). Of the patients who did not undergo cholecystectomy, five were CCKPT positive and 12 were CCKPT negative. Interestingly, after six months two patients in the former and nine in the latter group had spontaneous relief of symptoms.

HISTOLOGY OF RESECTED GALL BLADDERS Histological examination of the resected gall bladders showed changes of chronic cholecystitis in $84 \%$ while $16 \%$ of gall bladders were reported "normal". There was no correlation between preoperative CCKPT or postoperative symptomatic outcome and gall bladder histology.

\section{Discussion}

The currently accepted hypothesis regarding the origin of biliary pain is that it is caused by an abnormal pattern of contraction of the gall bladder with the neck contracting before the fundus. This "functional" gall bladder outflow obstruction may result in a reduced gall bladder ejection fraction and a rise in pressure in the gall bladder lumen which may cause pain. Stimulation of the gall bladder with cholecystokinin to reproduce this dysmotility forms the basis of the CCKPT. Assessment of this dysmotility may be subjective with the patient completing pain questionnaires after each test, or objective with measurement of gall bladder emptying either ultrasonographically or with HIDA (hydroxyindole diaminoacetic acid) scanning.

The CCKPT was introduced to improve the selection of patients with acalculous biliary pain who would benefit from cholecystectomy. ${ }^{13}$ Unfortunately, most studies ${ }^{911} 13-18$ report the results of cholecystectomy only on patients who had a positive test (pain reproduced after CCK administration) or those who had a reduced gall bladder ejection fraction, and the rate of symptom relief after surgery in these series varies from 70 to $94 \%$. Only a few studies ${ }^{2} 19{ }^{20}$ have reported the results of cholecystectomy on patients who had a negative test or those who had normal gall bladder ejection fractions, and all have failed to show a difference in the symptomatic outcome after cholecystectomy when compared with the CCKPT positive patients; our study confirms these results. An important study by Rhodes and coworkers ${ }^{5}$ has examined the value of the CCKPT and showed that symptom relief from cholecystectomy was not predicted by this test. In their series, of the 103 patients who were CCKPT positive, $67 \%$ had complete and $24 \%$ had partial symptom relief while eight of nine (89\%) CCKPT negative patients had symptom relief after cholecystectomy. The authors surprisingly concluded that patients who were CCKPT positive had an excellent chance of relief of symptoms. Our data could be misinterpreted in the same way if only the CCKPT positive patients were analysed.

CCK is known to stimulate a variety of organs other than the gall bladder, including the colon and duodenum. ${ }^{2122}$ This nonspecificity might explain the failure of the CCKPT to predict symptom relief. A high percentage of patients in our series who had positive preoperative CCK provocation tests became negative after removal of their gall bladders. This would indicate that CCK induces painful gall bladder contraction, because this pain disappears after the gall bladder is removed while the patient remains symptomatic. Even normal volunteers suffer pain in the right upper quadrant after CCK infusion, the mechanism of which is unclear ${ }^{23}{ }^{24}$; this adds substantial evidence that the CCK provocation test is not useful in the selection of patients who may have a better symptomatic outcome after cholecystectomy.

Patients whose gall bladders do not empty in response to CCK have been shown to have a better symptomatic outcome in previous studies. ${ }^{1418}{ }^{25}$ Gall bladder emptying is significantly reduced in CCKPT positive patients and this suggests gall bladder dysmotility. It is 
conceivable that a rise in intracholecystic pressure after CCK administration may account for the acute pain experienced by these patients. However, we were unable to show a correlation between gall bladder emptying and symptom benefit after cholecystectomy, suggesting that although the gall bladder might have abnormal motility, this is not the cause of the patients' symptoms. We have reported a follow up period of six months because this is sufficient time for the patients to recover from a cholecystectomy and symptom relief became evident during this period.

We conclude that approximately half of the patients with acalculous biliary pain in our study had symptom relief after cholecystectomy and pain reproduction or reduced gall bladder emptying after cholecystokinin provocation could not predict which patients would have benefited from surgery. Until a test which has a higher predictive value for the relief of symptoms is found, these patients may be offered a cholecystectomy but should be carefully counselled preoperatively regarding unpredictability of outcome.

1 Cozzolino H, Goldstein F, Greening R, et al. The cystic duct syndrome. $\mathcal{F} A M A$ 1963;185:100-4.

Dunn FH, Christenson EC, Reynolds J. Cholecystokinin cholecystography. FAMA 1974;228:997-1003.

3 Cohen WN, Freeman JB. Development and evaluation of use of cholecystokinin in the diagnosis of acalculous gallbladder disease. Can 7 Surg 1975;18:571-7.

4 Nathan MH, Newman A, Murray DJ. Cholecystokinin cholecystography. Four years evaluation. AfR Am f Roentgenol 1970;110:240-51.

5 Rhodes M, Lennard TWJ, Farndon JR. Cholecystokinin (CCK) provocation test: long term follow-up after cholecystectomy. Br f Surg 1988;75:951-3.

6 Davis GB, Berk RN, Scheible FW, et al. Cholecystokinin cholecystography, sonography and scintigraphy: detection cholecystography, sonography and scintigraphy: detection 1982;139:1117-21.

7 Raduns K, McGahan JP, Beal S. Cholecystokinin sonography: lack of utility in diagnosis of acute acalculous cholecystitis. Radiology 1990;175:463-6.
8 Goldberg HI. Cholecystokinin cholecystography, Roentgenology 1976;11:175-9

9 Yap L, Wycherley AG, Morphett AD, et al. Acalculous biliary pain: cholecystectomy alleviates symptoms in patients with abnormal cholescintigraphy. Gastroenterology 1991;101:786-93.

10 Middleton GW, Williams JH. Is gall bladder ejection fraction a reliable predictor of acalculous gall bladder disease? Nucl Med Commun 1992;13:894-6.

11 Lennard TWJ, Taylor RMR. Acalculous biliary pain: diagnosis and selection for cholecystectomy using the cholecystokinin provocation test for pain reproduction. $\mathrm{Br}$ f Surg 1984;71:368-70.

12 Melzack R. The McGill Pain Questionnaire: major properties and scoring methods. Pain 1975;1:277-99.

13 Sorenson MK, Fancher S, Lang NP, et al. Abnormal gallbladder nuclear ejection fraction predicts success of cholecystectomy in patients with biliary dyskinesia. Am $\mathcal{F}$ Surg 1993;166:672-4.

14 Zech ER, Simmons LB, Kendrick RR, et al. Cholecystokinin enhanced hepatobiliary scanning with ejection fraction calculation as an indicator of disease of the gallbladder. Surg Gynecol Obstet 1991;172:21-4.

15 Misra DC Jr, Blossom GB, Fink-Bennett D, et al. Results of surgical therapy for biliary dyskinesia. Arch Surg 1991;126: 957-60.

16 Reed DN Jr, Fernandez M, Hicks RD. Kinevac-assisted cholescintigraphy as an accurate predictor of chronic acalculous gallbladder disease and the likelihood of symptom relief with cholecystectomy. Am Surg 1993;59:273-7.

17 Neschis M, King MC, Murphy RA. Cholecystokinin cholecystography in the diagnosis of acalculous extrahepatic biliary tract disorders. Am $\mathcal{F}$ Gastroenterol 1978;70:593-9.

18 Jones DB, Soper NJ, Brewer JD, et al. Chronic acalculous cholecystitis: laparoscopic treatment. Surg Laparosc Endosc 1996;6:114-22.

19 Reid DRK, Rogers IM. The cholecystokinin test: an assessment. Br F Surg 1975;62:317-19.

20 Fink-Bennett D, DeRidder P, Kolozsi WZ, et al. Cholecystokinin cholescintigraphy: detection of abnormal gallbladder kinin cholescintigraphy: detection of abnormal gallbladder motor function in patients with chronic acal
gallbladder disease. 7 Nucl Med 1991;32:1695-9.

21 Coelho JCU, Moody FG, Senninger N, et al. Sphincter of Oddi and duodenum electromyography and common-duct pressures in the conscious opossum. Surgical Forum 1984;35:219-21.

22 Harvey RF, Read AE. Effects of cholecystokinin on colonic motility and symptoms in patients with the irritable bowel syndrome. Lancet $1973 ; \mathrm{i}: 1-3$

23 Krishnamurthy GT, Turner FE, Mangham D, et al. Ceruletide intravenous dose-response study by a simplified
scintigraphic study. AfR Am F Roentgenol 1985;144:733-7.

24 Sargent EN, Boswell W, Hubsher J. Cholecystokinetic cholecystography: efficacy and tolerance studies of cerucholecystography: efficacy and tolerance studies
letide. $A \mp R A m$ f Roentgenol 1978;130:1051-5.

25 Brugge WR, Brand DL, Atkins HL, et al. Gallbladder dyskinesia in chronic acalculous cholecystitis. Dig Dis Sci 1986; 31:461-7. 